\title{
Establishing boundary classes for the classification of UK marine waters using phytoplankton communities
}

\author{
Michelle Devlin ${ }^{\mathrm{a}}$, Mike Best $^{\mathrm{b}}$, Deborah Coates ${ }^{\mathrm{b}}$, Eileen Bresnan $^{\mathrm{c}}$, Shane O'Boyle ${ }^{\mathrm{d}}$, Richard \\ Park $^{\mathrm{e}}$, Joe Silke ${ }^{\mathrm{f}}$, Caroline Cusack ${ }^{\mathrm{f}}$, Joe Skeats ${ }^{\mathrm{g}}$ \\ ${ }^{a}$ Centre for Environment, Fisheries and Aquaculture Science, Pakefield Rd., Lowestoft NR3 3EJ, UK \\ ${ }^{\mathrm{b}}$ Environment Agency, EA Kingfisher House, Orton Goldhay, Peterborough PE2 5ZR, UK \\ ${ }^{\mathrm{c}}$ FRS Marine Laboratory, 375 Victoria Rd., Aberdeen, UK \\ d Environmental Protection Agency, Richview, Clonskeagh Road, Dublin, Ireland \\ ${ }^{\mathrm{e}}$ Scottish Environmental Protection Agency, Edinburgh, UK \\ ${ }^{\mathrm{f}}$ Marine Institute, Rinville, Oranmore, Galway, Ireland \\ ${ }^{g}$ Water Management Unit, Environmental and Heritage Service, Lisburn BT28 3AL, UK
}

\begin{abstract}
This paper presents a description of three of the proposed phytoplankton indices under investigation as part of a classification framework for UK and ROI marine waters. The three indices proposed for the classification process are (i) phytoplankton biomass measured as chlorophyll, (ii) the frequency of elevated phytoplankton counts measuring individual species and total cell counts and (iii) Seasonal progression of phytoplankton functional groups through the year. Phytoplankton biomass is calculated by a 90 th percentile measurement of chlorophyll over the growing season (April to September) compared to a predetermined reference value. Calculation of functional groups and cell counts are taken as proportional counts derived from the presence of the indicator species or group as compared to the total phytoplankton count.

Initial boundary conditions for the assessment of high/good status were tested for each index. Chlorophyll reference conditions were taken from thresholds developed for previous EU directives with the setting of offshore concentrations as a reference condition. Thresholds for elevated counts of phytoplankton taxa were taken from previous EU assessments describing counts that could be impact negatively on the environment. Reference seasonal growth curves are established using phytoplankton counts from "high status" waterbodies.

To test the preliminary boundaries for each index, a risk assessment integrating nutrient enrichment and susceptibility for coastal and transitional waters was carried out to identify WFD waterbodies in England and Wales at different levels of risk. Waterbodies assessed as having low or medium risk from nutrient enrichment were identified as type 1 and type 2 waterbodies, and waterbodies assessed as high risk were identified as type 3 waterbodies. Phytoplankton data was extracted from the risk assigned waterbodies and applied to each phytoplankton index to test the robustness of the preliminary classification ranges for each phytoplankton index.
\end{abstract}

Keywords: Nutrients; Phytoplankton; Functional groups; Water Framework Directive; Boundary conditions; Classification techniques

\section{Introduction}

The overall aim of the Water Framework Directive (CEC, 1991, 2000) is to establish good ecological status in all European waters by 2015. Phytoplankton, along with benthic invertebrates, estuarine fish and macrophytes are known as biological quality elements in the WFD process. The WFD directive uses a "classification scheme" for the overall classification of the waterbody which includes some measure of these biological elements. Classification is a way of reporting the state of the environment and provides a 
way of comparing waters and looking at changes over time and "classification tools" are used for assessing the status of each individual quality element against high status (Vincent et al., 2002). Accordingly, the ecological status is expressed as a ratio between the values of the biological elements observed by a given body of surface water and the values for these elements in a site with no, or very minor, disturbance from human activities (reference ecological status). The WFD provides general definitions for the first three quality conditions or classes (high, good, and moderate), known as the "normative definitions". Each describes a different degree of impact on the plants and animals. Member states are responsible for further defining these and providing definitions for the poor and bad classes.

Assessments relating to phytoplankton are required to encompass taxonomic composition, abundance, biomass and plankton blooms for the ecological classification of transitional and coastal waters (CEC, 1991, 2000). More specifically the wording of the directive states that if a water body is to attain "high" ecological status "the composition and abundance of phytoplanktonic taxa are to be consistent with undisturbed conditions". Phytoplankton succession and community composition reflect the environmental conditions of the ecosystem, among which nutrient availability plays a significant role (Sommer, 1989; Gallegos et al., 1992; Bemen et al., 2005) in structuring that community. The primary biological response to nutrient enrichment in aquatic environments, given suitable environmental conditions (such as light availability and water temperatures), is the growth of phytoplankton and higher plants. Known consequences of marine eutrophication on the phytoplankton community include elevated chlorophyll levels (Boynton et al., 1996; Bricker et al., 2003), red tides, water discolouration and foaming - such as that caused by the colonial flagellate Phaeocystis pouchetii in the southern North Sea (Lancelot et al., 1987), increased production, which may give rise to extra biochemical oxygen demand (BOD) and hence increased removal of oxygen, in enclosed waters resulting in local anoxia. These include sea-lochs such as Striven (Tett et al., 1986) and the Baltic Sea (Larsson et al., 1985). Other consequences include shifts in species composition, from diatoms to flagellates (Gillbricht, 1988). In general terms, nutrient input is assumed to result in the rapid growth of opportunistic, fast growing primary producers and the accumulation of extra biomass which may have a negative impact on the ecosystem. Other attributes considered to be symptoms of negative impacts of nutrient enrichment include blooms of toxic algae, increased growth of epiphytic algae, the growth of nuisance macroalgae, the loss of submerged vegetation due to shading, the development of hypoxic (and anoxic) conditions due to decomposition of the accumulated biomass, and changes in the community structure of benthic animals due to oxygen deficiency or the presence of toxic phytoplankton species (see Bricker et al., 1999, 2003; Tett, 1987; Smayda and Reynolds, 2001). The potential ecological ramifications of nutrient enrichment and disturbance also include alterations of the natural phytoplankton community composition, which may in turn change ecosystem food web and nutrient cycling dynamics. For example, if the growth of more readily grazed phytoplankton functional groups (e.g. diatoms) is favoured, trophic transfer and nutrient cycling will take place largely in the water column, with enhanced export of the assimilated algae (as fish) to marine waters. In contrast, if the nutrient loading favours phytoplankton functional group that may not be readily grazed (e.g. dinoflagellates), tropic transfer will be poor and relatively large amounts of unconsumed algal biomass will ultimately settle to the bottom. This unconsumed biomass will stimulate microbial decomposition and oxygen consumption, exacerbating the potential for the development of hypoxia conditions and alterations in the food chain.

Despite the complexities associated with the phytoplankton community, there are general characteristics of the phytoplankton community which can be explored to identify indicators of ecosystem function and change linked to nutrient enrichment. Other common indices or attributes of the phytoplankton population that have been used in ecological assessments include bulk measurements of biomass and abundance (OSPAR, 2003; CSTT, 1994, 1997), taxon diversity (Karydis and Tsirtsis, 1996), seasonal succession (Hallegraeff and Reid, 1986; Belin et al., 1995; Gailhard et al., 2002) and indicator species (Edwards et al., 2001; Paerl et al., 2003). Phytoplankton biomass has typically been used as indicators of nutrient enrichment (CSTT, 1997; Malcolm et al., 2002; Gowen et al., 1992; Painting et al., 2005). Phytoplankton biomass is a direct measurement of the phytoplankton abundance and in UK waters, it should reflect low numbers in the winter, high spring concentrations, and variable, periodic summer and autumnal blooms. Chlorophyll concentrations represent a very simple and integrative measure of the phytoplankton community response to nutrient enrichment. Increase in the phytoplankton biomass can be measured as an increase in the chlorophyll concentrations. Chlorophyll is a useful expression of phytoplankton biomass and is arguably the single most responsive indicator of $\mathrm{N}$ and $\mathrm{P}$ enrichment in the marine system (Harding, 1994).

A number of these ecological assessment schemes using phytoplankton have identified the use of response ranges in water types and separate out types based on a gradient response. Differences in phytoplankton responses along a gradient can be used to set a scale for WFD boundary assessments within the phytoplankton community.

Development of all classification tools under the Directive must relate to the normative definitions as set out in the Directive guidelines. Phytoplankton normative definitions encompass the composition and abundance of phytoplanktonic taxa, phytoplankton biomass and blooms. These definitions serve as an anchor on which we have established simple qualitative measurements related to increases in blooms, biomass and phytoplankton abundance. The difficulty lies, as with all of the WFD biological 
elements, in providing a reference value to which all other measurements are anchored against to deliver a robust ratio which aligns to WFD ecological boundaries. The directive recognises these potential problems in Europe's modified marine waterbodies and identifies a number of ways to assess reference conditions, including historical analysis, spatial comparison of type similar waterbodies, the use of models and expert judgement (Vincent et al., 2002; CEC, 1991, 2000).

Classification tools have been developed based on expert knowledge, previously accepted criteria and use of historical phytoplankton data. Reference conditions are calculated using historical data from low risk (of nutrient enrichment) waterbodies to establish preliminary boundary classes to be tested as part of the ongoing phytoplankton classification process.

\section{Methodology}

\subsection{Phytoplankton data}

To meet the requirements of WFD (CEC, 1991, 2000), a comprehensive UK phytoplankton database (Water Framework Directive Marine Phytoplankton Database) has been compiled covering data from five regions (England, Wales, Scotland, Northern Ireland and Republic of Ireland), with data spanning a temporal range of 23 years. The database presently holds 225,119 phytoplankton taxa records from 30,453 samples, taken at 1441 sampling stations. This data covers samples for 147 out of 682 coastal water bodies and 78 out of 435 transitional water bodies. Sampling sites throughout the UK and Republic of Ireland (ROI) are presented in Fig. 1.

Historically phytoplankton data have been collected for many different purposes therefore full species analysis of samples, which is required for WFD, was not always carried out. Some analysis was only for dominant species and/or nuisance and toxic species. There are limited long term, high temporal frequency data sets available, however the WFD UK and ROI Marine Phytoplankton Database is the largest and most complete record of UK and ROI phytoplankton data in transitional and coastal waters.

All phytoplankton data entered into the database has been fully quality assured and stored against a standardised UK and ROI phytoplankton taxa list. The standardised phytoplankton taxa list has been fully validated by taxonomic experts. For every data set entered into the database, quality checks on species names, counts and sampling locations were made throughout the data entry process.

The cell count component of index 2 and 3 is calculated from the taxonomic composition of phytoplankton from coastal and transitional waters determined from samples collected and freshly fixed at sea. Microscopic analysis involves counting and identifying the phytoplankton to species; allocating broad functional groups of diatoms, dinoflagellates and micro flagellates.
Sampling time is defined as all phytoplankton groups or species counted and identified over sampling date or Julian month (0-12) for one waterbody with a minimum sampling period of six years, which aligns to the WFD assessment period. This could comprise a number of locations within the one waterbody. Sampling frequency should be no less than 12 times per year, collected monthly, over the sampling year. Phytoplankton abundance is measured as a count of a functional group or species within the total phytoplankton sample. Phytoplankton counts are integrated over each waterbody by combining all sampling occasions within that waterbody over the WFD sampling period.

\subsection{Development of classification boundaries for WFD assessment}

UK classification based on phytoplankton encompasses a number of diagnostic tools which measure the potential consequences of marine eutrophication and link to the Directive's normative definitions. Monitoring tools should be able to discriminate between the five WFD quality classes, measuring anthropogenically induced deviation from reference conditions. The Directive does not define reference conditions, other than to state that they should be established, be type specific and represent conditions free from anthropogenic influences. "Good" and "moderate" deviations from reference conditions similarly are defined only qualitatively by the WFD. Table 1 describes the three potential indices, and lists previous directives in which similar indices have been utilised, and the type specific reference conditions that will be developed for each index. A description of the indices and literature reviewed thresholds are presented for chlorophyll concentrations and phytoplankton counts. For seasonal progression, establishment of a reference seasonal growth curve is described, as limited information exists on the use of phytoplankton growth patterns as an assessment tool. Each index is tested against phytoplankton data extracted from WFD coastal waterbodies. The waterbodies were assigned a risk factor (low, medium and high risk) based on the nutrient concentrations and the susceptibility to nutrient enrichment. The assigned risk classes were then used to establish preliminary classification ranges for the WFD boundary classes.

\subsection{Type specific classification boundaries}

Transitional waters and coastal waters were grouped mainly on the basis of natural characteristics that might influence ecological communities - altitude, latitude, longitude, geology and size. The method, by which waters of similar ecological sensitivity are grouped into types for the Directive, is referred to as a typology (Rogers et al., 2003). For example, to assign transitional (estuarine) waters to types we used a typology based on exposure and mixing.

Phytoplankton boundary conditions which set the classification for the Water Framework Directive may be type 


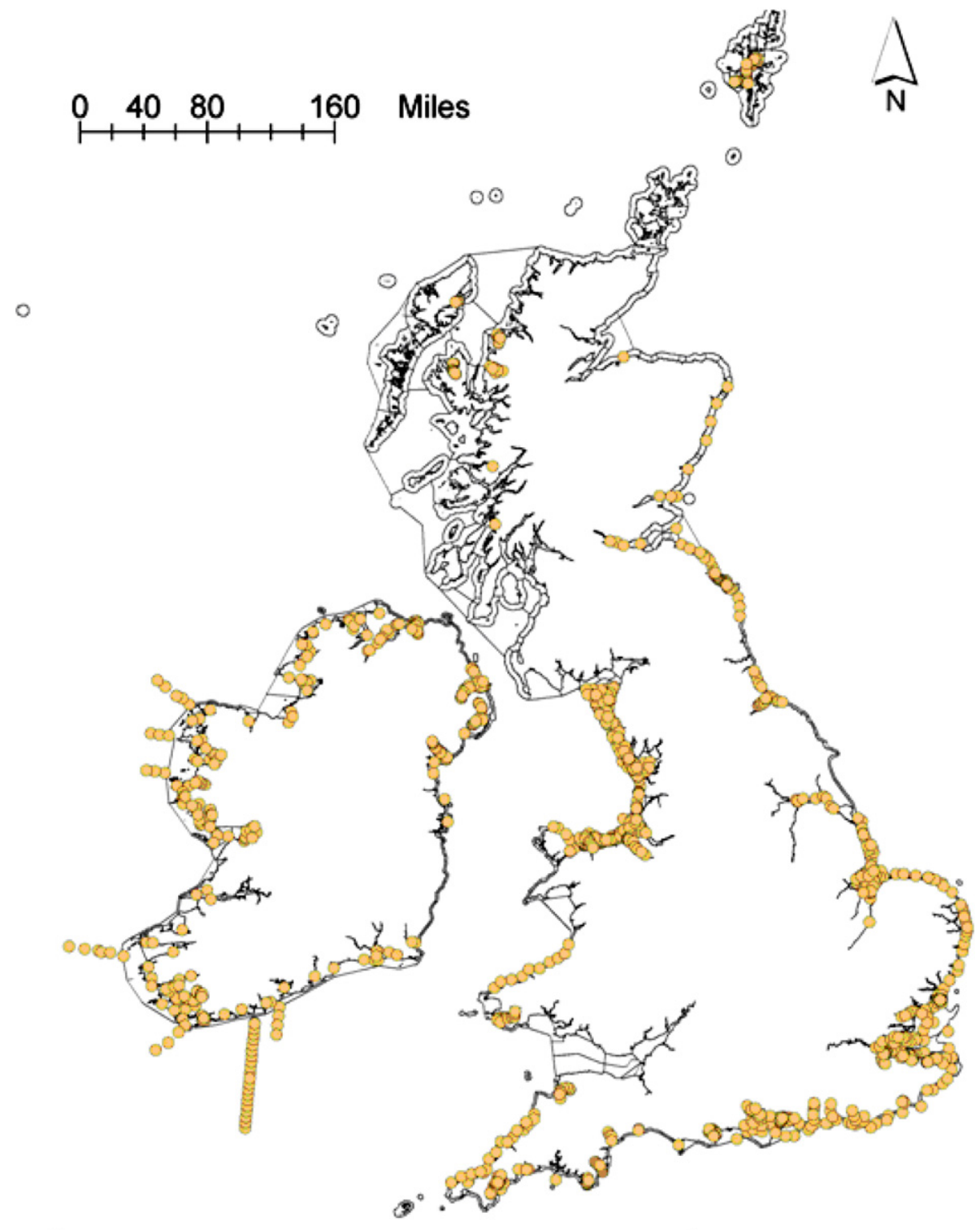

UK and ROI Phytoplankton Sampling Sites

Fig. 1. Phytoplankton sampling sites located around the UK and ROI. WFD typologies (CW1 to CW12 and TW1 to TW6) are shown on map.

specific - different types of waters will have different boundaries. Alternatively in developing these classification tools, we have found, in some cases, that it is appropriate to use a single classification for several or all types. In other cases, we have used a number of types (Table 1). A better understanding of the environment through future monitoring, will allow the refinement and development of type specific reference conditions and potentially amend some of the classification boundaries. This paper will only focus on establishing classification ranges for coastal waterbodies, as the phytoplankton response in transitional waterbodies can be confusing due to the physical environment and the strong gradients of river flow, circulation, tidal mixing, nutrient inputs, turbidity and variable salinity range (Kocum et al., 2002).

\subsection{Use of risk assessment to test initial boundary classifications}

A risk index of waterbodies based on the level of nutrient enrichment and susceptibility of the waterbody to enrichment was established, allocating a risk factor to waterbodies within England and Wales only. The levels of risk (low, moderate or high) were selected based on nutrient loading and nutrient concentrations and the susceptibility of waterbody to nutrient enrichment. The risk index was calculated from a combination of nutrient enrichment, susceptibility (light availability) and physical conditions. A summary of the factors used to assign risk is shown in Table 2 and further discussion of the risk methodology can be found at www.characterisationqualityreview.org.uk. High risk 
Table 1

Details of phytoplankton indices suggested for UK WFD classification

\begin{tabular}{|c|c|c|c|}
\hline $\begin{array}{l}\text { Phytoplankton } \\
\text { response }\end{array}$ & Increases in chlorophyll biomass & Elevated counts of phytoplankton taxa & Alterations in the seasonal succession \\
\hline $\begin{array}{l}\text { Historical } \\
\text { directives }\end{array}$ & \multicolumn{2}{|c|}{$\begin{array}{l}\text { CSTT (CSTT, 1994, 1997) OSPAR (Malcolm et al., 2002), ECOQO's (Painting et al., } \\
\text { 2005) }\end{array}$} & Not previously used in UK assessments \\
\hline $\begin{array}{l}\text { Description of } \\
\text { previous } \\
\text { assessment } \\
\text { criteria }\end{array}$ & $\begin{array}{l}\text { Maximum and mean chlorophyll } \\
\text { concentrations during the growing season } \\
\text { should remain below elevated levels, } \\
\text { defined as concentrations }>50 \% \text { above the } \\
\text { spatial (offshore) and/or historical } \\
\text { background concentration }\end{array}$ & $\begin{array}{l}\text { Region/area-specific phytoplankton } \\
\text { eutrophication indicator species should } \\
\text { remain below respective nuisance and/or } \\
\text { toxic elevated levels (and increased } \\
\text { duration) }\end{array}$ & $n / a$ \\
\hline $\begin{array}{l}\text { Reference } \\
\text { conditions }\end{array}$ & $\begin{array}{l}\text { Generic reference concentration developed } \\
\text { for all coastal water bodies (CW's) }\end{array}$ & $\begin{array}{l}\text { Generic reference concentration developed } \\
\text { for all coastal water bodies (CW's) }\end{array}$ & $\begin{array}{l}\text { Reference conditions developed for type } \\
\text { specific waterbodies (CW2, CW4, CW5 } \\
\text { and CW7). Further work needed to } \\
\text { identify a generic reference type or further } \\
\text { data collection to identify type specific } \\
\text { references for other CW's }\end{array}$ \\
\hline $\begin{array}{l}\text { Normative } \\
\text { definition } \\
\text { (WFD) }\end{array}$ & Phytoplankton biomass & Phytoplankton blooms and abundance & Phytoplankton blooms and abundance \\
\hline $\begin{array}{l}\text { WFD } \\
\text { assessment } \\
\text { description }\end{array}$ & $\begin{array}{l}I_{\text {chl }}: \text { Chlorophyll concentration calculated } \\
\text { by the } 90 \text { th percentile }\left[X_{90 \mathrm{th}}\right] \text { of all } \\
\text { chlorophyll data }\end{array}$ & $\begin{array}{l}I_{\mathrm{E}} \text { : Sum of the occurrence of any single } \\
\text { species }\left(>10^{6}\right) \text { plus Phaeocystis sp. }\left(>10^{5}\right) \text {, } \\
\text { plus total cell counts }\left(>10^{7}\right) \text { and counts of } \\
\text { chlorophyll }>10 \mu \mathrm{g}^{-1} \text { over a six year } \\
\text { period }\end{array}$ & $\begin{array}{l}I_{S}: \text { Sum of the occurrences of calculated } Z \\
\text { score ( for each functional groups) that } \\
\text { falls outside predefined growth envelope }\end{array}$ \\
\hline Notation & $I_{\mathrm{chl}}=X_{90 \mathrm{th}}\left[C_{1}, \ldots, C_{i}\right]$ & $I_{\mathrm{E}}=\sum[\mathrm{chl}+S+P+T]$ & $I_{S}=\sum\left[I_{\text {diat }}+I_{\text {dino }}+I_{\mathrm{f}}+I_{\mathrm{p}}\right]$ \\
\hline
\end{tabular}

Table 2

Calculation of risk index for transitional and coastal waters (England and Wales)

\begin{tabular}{|c|c|c|c|c|}
\hline WB & Pressure & Attribute & Factors influencing risk of enrichment & Sources of data \\
\hline \multirow[t]{2}{*}{$\begin{array}{l}\text { Transitional } \\
\text { waters } \\
\text { (TW) }\end{array}$} & Source & $\mathrm{N}$ loading into $\mathrm{TW}$ & $\begin{array}{l}\text { Water residence times (proxy for } \mathrm{N} \text { loss) Flushing characteristics } \\
\text { based on tidal range and freshwater inflow/estuary volume } \\
\text { Sensitivity based on mixing characteristics of TW (dilution } \\
\text { potential) Nitrogen load }\left(\mathrm{kg} \mathrm{N} / \text { day } / \mathrm{km}^{2}\right)\end{array}$ & $\begin{array}{l}\text { Harmonised monitoring } \\
\text { data PARCOM Sewage } \\
\text { inputs }\end{array}$ \\
\hline & Exposure & $\begin{array}{l}\text { Winter nutrient } \\
\text { concentrations (salinity } \\
\text { based thresholds) }\end{array}$ & $\begin{array}{l}\text { Winter nutrient (DIN) concentrations along a salinity gradient } \\
\text { Sensitivity matrix based on nutrient concentrations and } \\
\text { turbidity (in absence of turbidity/light data, tidal range will be } \\
\text { used as proxy with macro-tidal considered least sensitive) }\end{array}$ & UK nutrient data \\
\hline
\end{tabular}

Outputs from risk assessment assigned high, moderate and low risk to $x$ waterbodies within England and Wales.

waterbodies are indicative of waterbodies that would be more likely to demonstrate a negative impact from nutrient enrichment and identified as type 3 waterbodies. Waterbodies assessed as low risk from nutrient enrichment were more likely to be high status waterbodies and are identified as type 1 waterbodies. Moderate risk waterbodies are identified as type 2 waterbodies (Table 2). These risk assigned waterbodies were used to develop classification ranges for each of the phytoplankton indices.

It is important to note that risk assessment is not classification and not all high risk waterbodies will necessarily demonstrate eutrophication symptoms. However, in the absence of any previous phytoplankton classification scheme at a WFD waterbody level, it was deemed appropriate for preliminary classification. Classification boundaries that are identified would need continual monitoring for further confidence in assessment.
Outcomes from the risk assessment were used to test the boundary conditions suggested for index 1 (chlorophyll biomass) and index 2 (elevated count index). However, as there is limited information on index 3 (succession of functional groups) as an assessment tool, the type 1 waterbodies (potentially high ecological status) were used to construct the seasonal characteristics that are comparative to a high status condition. Data from all the risk assigned waterbodies were then used to define ranges for each classification boundary.

\section{Index 1 - Phytoplankton biomass}

\subsection{Description of index}

EU directives for eutrophication assessment (Table 1) have all utilised chlorophyll biomass in previous assessments. 
We propose to use a similar index as documented in OSPAR (Malcolm et al., 2002) and European Ecological quality objectives (EcoQo's) (Painting et al., 2005). The index used in OSPAR and EcoQo's is described as

- Maximum and mean chlorophyll concentrations during the growing season should remain below elevated levels, defined as concentrations $>50 \%$ above the spatial (offshore) and/or historical background concentration.

However it is argued that neither mean nor maximum give a good overview of the chlorophyll measurement (Clarke and Warwick, 1994). Maximum values are not applicable when sampling numbers are small and non-continuous and mean values can mask skewness in the data. Environmental data such as phytoplankton chlorophyll exhibits periodicity and episodic change and as a result tends to be asymmetrically distributed with few high values (outliers or spikes) and many low values. A recognised statistical approach is to derive 90th percentile values as a bulk measurement of the data (Atchinson, 1986; Clarke and Warwick, 1994). The 90th percentiles represented a statistical method encompassing the spread of data for chlorophyll biomass omitting highly skewed values, which can be present during bloom periods. Phytoplankton biomass index can be measured as chlorophyll concentration and is calculated as a 90th percentile of all chlorophyll data collected over the growing season (March to September inclusive). The 90th percentile value is compared with the threshold value derived from appropriate reference conditions. Thus the index can be rewritten for WFD assessment as

- 90th percentile chlorophyll concentrations during the growing season (March to September) should remain below thresholds set for the high/good and good/moderate boundaries for type specific conditions.

\subsection{Defining boundary conditions}

In previous directive, the boundaries for chlorophyll are based on a justified area-specific \% deviation from background chlorophyll concentrations. Background conditions are based on a deviation from Atlantic background concentrations (OSPAR, 2003; Gowen et al., 2002) where available. For the OSPAR Comprehensive Procedure, appropriate standards for assessing chlorophyll concentration were derived from the background nutrient concentrations by making some reasonable assumptions about nutrient conversion to plant biomass (Malcolm et al., 2002; Painting et al., 2005). There was considerable uncertainty in the calculated background level due to the wide range of factors that could be used to convert carbon to chlorophyll. From practical experience the UK has adopted $10 \mu \mathrm{g}^{-1}$ chlorophyll as a guide for assessment. It was therefore proposed that
- for offshore waters, $10 \mu \mathrm{g} 1^{-1}$ chlorophyll is adopted as the reference value (implying 50\% elevation of the background value of $6.7 \mu \mathrm{g}^{-1}$ and a reasonable C:Chl factor of 0.012 ) and

- for nearshore waters, where the level of production may be expected to be higher, $15 \mu \mathrm{g}^{-1}$ chlorophyll is adopted as the reference value (implying a background value of $10 \mu \mathrm{g}^{-1}$ chlorophyll and a C:Chl factor of $0.02)$.

As WFD classification is related to five boundaries and not a pass/fail threshold, the offshore reference value has been used as the starting point for high classification and we will align the good/moderate boundary with the $50 \%$ elevation of the reference threshold (see Vincent et al., 2002; Malcolm et al., 2002). The other thresholds are based on a deviation away from this high/good and good/moderate threshold. Final classification is based on the calculation of the 90th percentile of all chlorophyll data collected within a waterbody over the growing season. It is worth noting that the original reference factor was described for a mean, and using this against a 90th percentile supports a more precautionary approach to the recommended threshold. Chlorophyll data from the risk assigned waterbodies was extracted, 90th percentiles calculated and plotted against the three types of risk categories to test the robustness of these boundary conditions.

\section{Index 2 - Elevated phytoplankton abundance}

\subsection{Description of index}

Persistent, high cell counts of any algae can lead to over production and impact on ecology of the waterbody. This index $\left(I_{\mathrm{E}}\right)$ is designed to assess if the presence, abundance and frequency of occurrence of elevated counts of algal species correspond to undisturbed conditions (Belin et al., 1995). The tool is composed of four attributes, one which is a measure of the frequency that elevated biomass [chl] exceeds a reference threshold and three of which focus on counts of algae that may result in the decline of ecosystem health or result in an undesirable disturbance (Tett, 2004) (Table 4).

The classification tool works by recording the number of events, defined by sampling occasions when the sum of the four attributes exceeds these predefined thresholds over the period of the monitoring programme. Each attribute is calculated from the number of times that the sub-metric exceeds the threshold as a proportion of the total number of sampling times and calculated as a six year mean. Final classification score is based on the mean of all four attributes (as a \%).

\subsection{Defining boundary conditions}

Thresholds for each attribute were constructed based on a combination of scientific review (Belin et al., 1995; 
Gailhard et al., 2002; Bricker et al., 2003; Borja et al., 2004), thresholds accepted in previous directives (CSTT, 1997) and expert knowledge (Marine Phytoplankton Task Team, www.wfduk.org). The proposed thresholds are for three groups of phytoplankton and for counts of chlorophyll exceeding a threshold. The first phytoplankton threshold identifies any species of phytoplankton, excluding Phaeocystis species, that exceed counts of $10^{6}$ cells $1^{-1}$ [S], the second phytoplankton threshold identifies Phaeocystis $\mathrm{sp}$. that exceed counts of $10^{6}$ cells $1^{-1}[P]$, and the third threshold identifies where the total taxa counts exceeds counts of $10^{7}$ cells $1^{-1}[T]$. Details of each attribute and corresponding thresholds can be found in Table 4 . The chlorophyll count within this index identifies any chlorophyll measurement that exceeds $10 \mu \mathrm{g} 1^{-1}$.

Risk assigned waterbodies were used to develop classification boundaries for each of the attributes, using an overall percentage based on occurrence of any of the four attributes exceeding the threshold. Phytoplankton counts from low, moderate and high risk waterbodies were calculated for each of the attributes of this index and added together for an overall percentage. Phytoplankton data from the risk allocated waterbodies are tested against the proposed thresholds to establish a range of exceedances (measured as a \% of total sampling times) which would be analogous to high, good, and moderate boundary conditions.

\section{Index 3 - Seasonal succession of functional groups}

\subsection{Description of index}

A shift in functional groups may affect ecosystem function in terms of the carbon available to higher trophic levels or settling to the sediments. It is not clear how such shifts affect, or are affected by, diversity and ecosystem function, however succession of functional groups can potentially provide an index $\left(I_{\mathrm{f}}\right)$ that represents a healthy planktonic system, with a natural progression of dominant functional groups throughout the seasonal cycle. Seasonal succession has not been applied as an assessment tool in previous UK directives, so seasonal distribution curves were developed for waterbodies across UK using the phytoplankton data extracted from type 1 waterbodies (low risk). Counts of four major functional groups, including diatoms, dinoflagellates, microflagellates (excluding Phaeocystis) and Phaeocystis sp. are averaged for each month over a sampling year. Counts are highly skewed, due to the seasonal abundances of the functional groups and the high counts of microflagellates and Phaeocystis sp. Skewed data is accounted for by the transformation of phytoplankton counts on a natural log scale.

\subsection{Establishment of reference thresholds}

Fig. 2 describes the process of establishing reference growth curves for WFD waterbodies. The process entails the extraction of phytoplankton data, identified to one of the functional groups or Phaeocystis sp. Phytoplankton counts are averaged over months, and monthly mean $\left(x_{i}\right)$ and standard deviations calculated for each functional group. A process of normalisation, transformation and calculation of a monthly $Z$ score establishes comparable seasonal distributions for each functional group for a sampling year (Fig. 2). A positive $Z$ score indicates that the observation is greater than the mean and a negative score indicates the observation is less than the mean. $Z$ scores of zero illustrate the monthly sample approaches the overall mean for that sampling period. Generic reference curves were established for coastal water type CW2, (exposed), CW4, CW5 (moderately exposed) and CW7 (sheltered) waterbodies only (Fig. 3). Reference curves for other waterbodies were not established due to limitations of data and/or the lack of a high status waterbody on which to extract seasonal growth curves. At this stage, the reference curves only apply to England and Wales waterbodies, where the risk assessment was carried out. Further work on growth curves in Scottish, Northern Ireland and Irish waterbodies is warranted before inclusion of reference growth curves from these waterbodies.

\subsection{Defining boundary conditions}

Risk outputs from the three types of waterbodies (type 1,2 , or 3 ) have been used to establish generic classification boundaries for the seasonal succession tool. The phytoplankton counts from waterbodies were logged on a natural scale and monthly $Z$ scores were calculated for each waterbody type.

Monthly $Z$ scores for each functional group for all test waterbodies were compared to the type specific reference curve set out in Fig. 3. The score was based on the number of data points from the test waterbody which fell within the standard deviation range set for each monthly point of the reference growth curve. A \% calculation was taken of the points that fell within the growth curve relative to the overall sampling points. Percentage based thresholds were established for each functional group to determine if the outputs from the low, moderate and high risk waterbodies was significantly different to establish class boundaries.

\section{Results}

\subsection{Chlorophyll concentrations}

Chlorophyll concentrations were calculated for each risk group (type 1,2, and 3). The number of waterbodies used in the analysis was 17,6 and 7 respectively for type 1,2 and 3 waterbodies (Table 3). A significant linear regression $\left(r^{2}=0.7\right)$ exists between the risk classes, suggesting that the risk categories are comparable to a phytoplankton response (Fig. 4). All of the 17 low risk waterbodies fell below the $10 \mu \mathrm{g}^{-1}$ threshold, with all 6 medium risk waterbodies falling below the $15 \mu \mathrm{g} 1^{-1}$ supporting the 


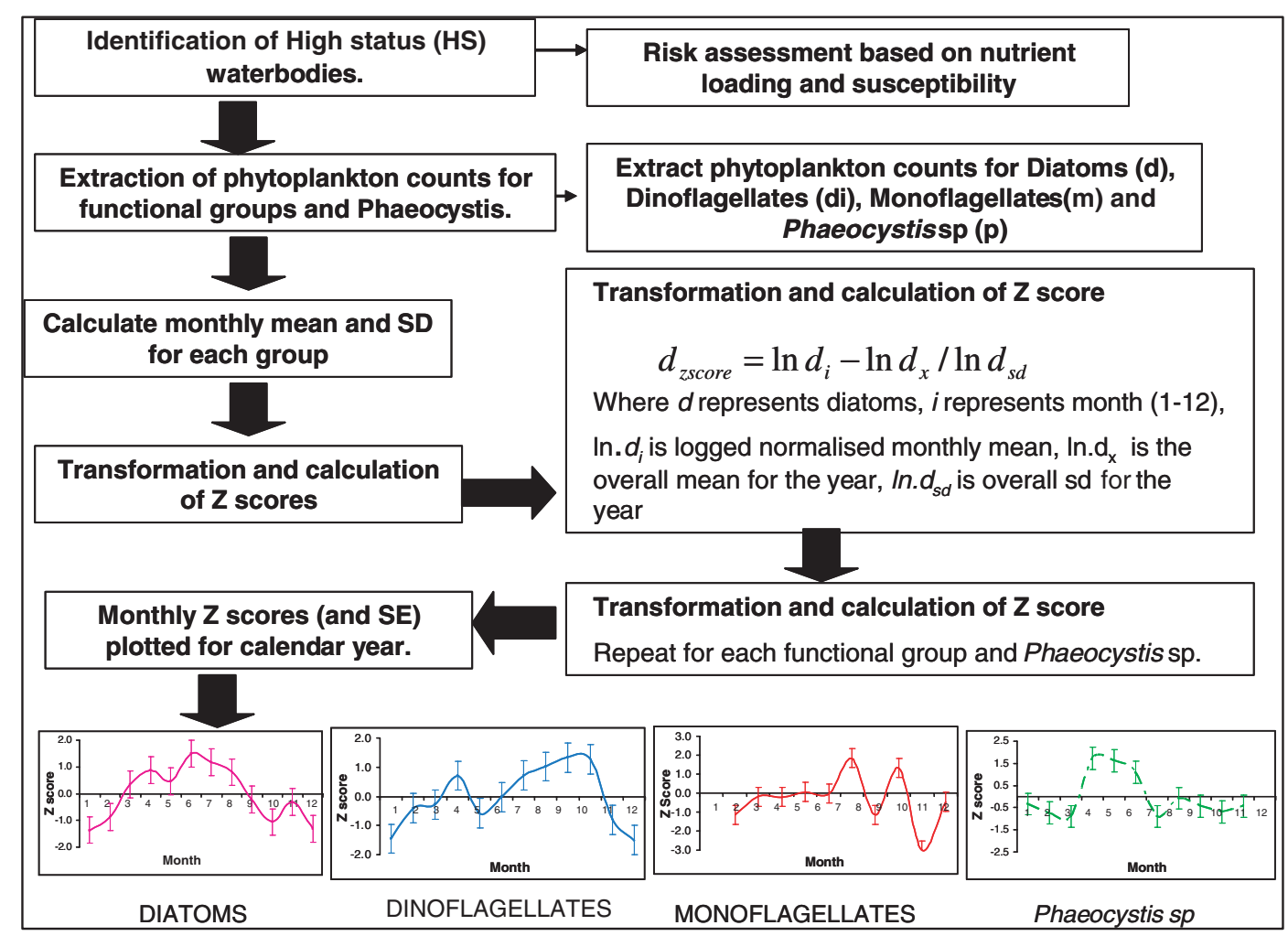

Fig. 2. The process of setting reference growth curves for the seasonal succession of four phytoplankton groups, including diatoms, dinoflagellates, monoflagellates and Phaeocystis sp.

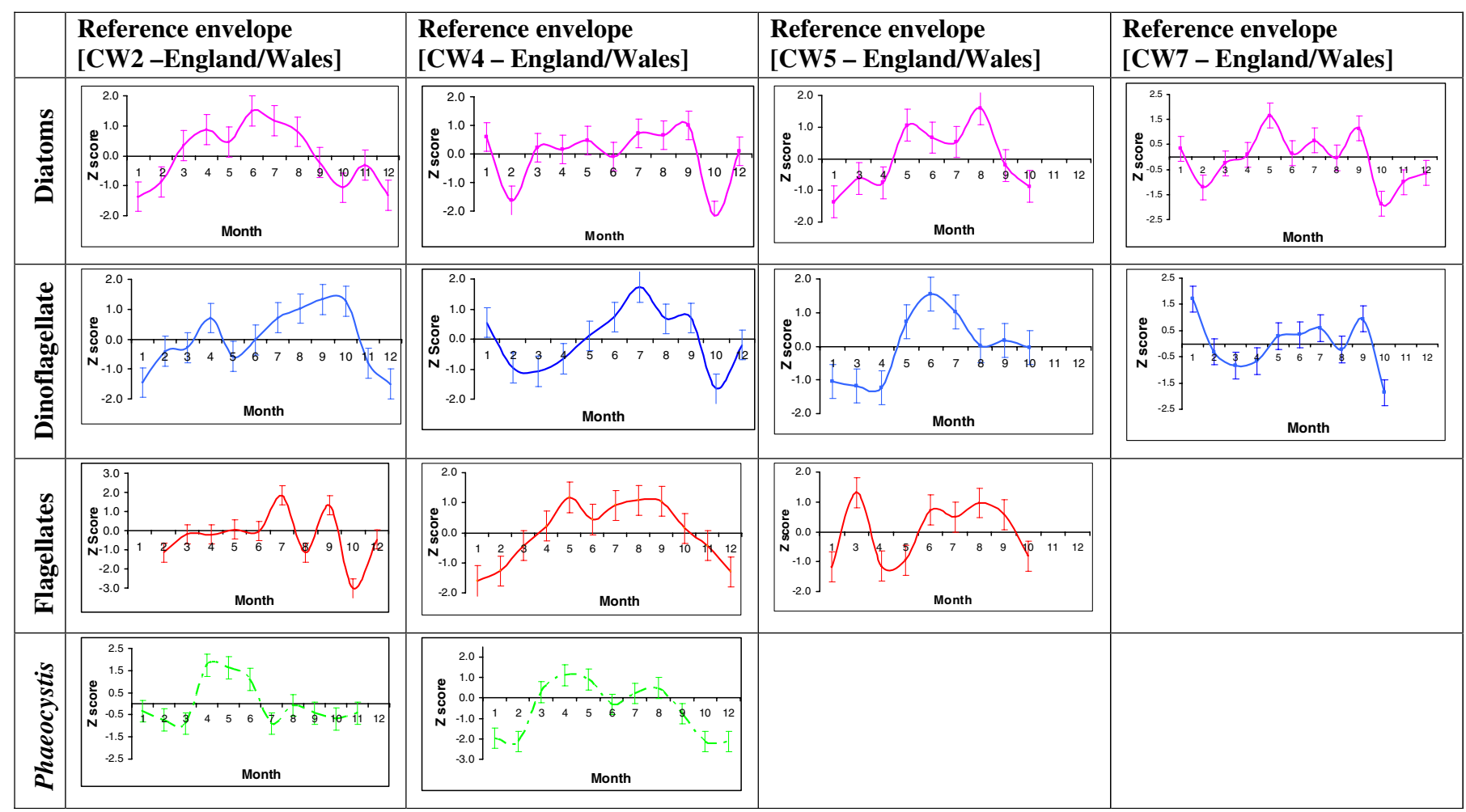

Fig. 3. Reference growth envelopes for CW2, CW4, CW5 and CW7. Monthly $Z$ scores with 1 degree of error are presented for each month. Mean $Z$ score for each functional group (0) is identified by dotted line. Absence of growth envelope (CW5, CW7) denotes lack of sufficient data to establish a reference curve. 
Table 3

Summary of risk assigned waterbodies used in the setting of reference conditions and the setting of boundary conditions

\begin{tabular}{lllrll}
\hline $\begin{array}{l}\text { Risk } \\
\text { outcome }\end{array}$ & $\begin{array}{l}\text { Risk } \\
\text { type }\end{array}$ & $\begin{array}{l}\text { Boundary } \\
\text { condition }\end{array}$ & \multicolumn{3}{c}{ Counts used in analysis } \\
\cline { 5 - 6 } & & & Chlorophyll & $\begin{array}{l}\text { Elevated } \\
\text { counts }\end{array}$ & $\begin{array}{l}\text { Seasonal } \\
\text { succession }\end{array}$ \\
\hline Low & 1 & High status & 17 & 11 & 7 \\
Moderate & 2 & Good status & 5 & 11 & 8 \\
High & 3 & $\begin{array}{l}\text { Moderate } \\
\text { (and below) }\end{array}$ & 7 & 18 & 7 \\
\hline
\end{tabular}

$\overline{\text { Boundary condition identifies the classification status that is comparable }}$ to the risk type.

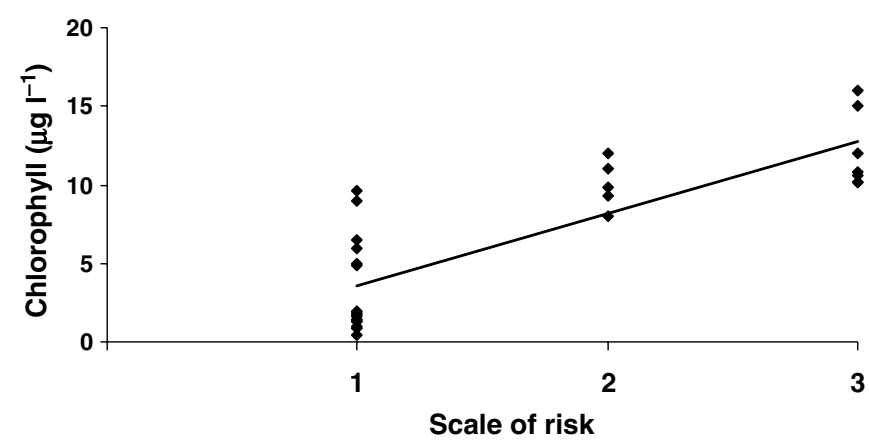

Fig. 4. Chlorophyll concentrations (averaged over water body type) corresponding to a scale of risk. Risk is defined as low risk (type 1), medium risk (type 2) and high risk (type 3 ).

recommended thresholds of 10 and 15 for high/good and good/moderate boundaries. However, only 2 of the high risk waterbodies (type 3 ) exceeded $15 \mu \mathrm{g} 1^{-1}$. Thus thresholds for high and good classes were accepted, noting that further work on the moderate/poor and poor/bad classification boundaries levels is warranted (Table 5). Further scrutiny of existing data, as well as the acquisition of new data, are required before these can be determined with appropriate confidence. Proposed class boundaries to date are summarised in Table 5.

\subsection{Elevated counts}

Outputs from the Elevated counts classification tool $\left(I_{\mathrm{e}}\right)$ were plotted for each waterbody against the assigned risk classes. The low and medium risk waterbodies all fell below $25 \%$ of exceedances calculated from the mean of all four attributes (Table 4). However the high risk waterbodies were spread over a range of $18-100 \%$ exceedances (Fig. 5). To identify potential high/good boundaries within the $25 \%$ range of exceedances, outputs from the low and medium risk waterbodies were ranked from lowest to highest \% counts (Fig. 6). Using these ranked scores an arbitrary break at $10 \%$ was set for the high/good boundary and a score of $25 \%$ was set for the good/moderate boundary. Further boundary classes were set at $65 \%$ and $50 \%$ for moderate/poor and poor/bad boundary classes respectively (Table 6).

\subsection{Seasonal succession of phytoplankton}

Fig. 3 shows the seasonal distribution of the three functional groups and Phaeocystis sp., confirming the opposition of winter summer species and spring-fall species, and allows the succession of communities to be described for each of the coastal types. The seasonal progression from diatom to dinoflagellate-dominated communities illustrates the basic characteristics of phytoplankton succession in temperate coastal waters (Smayda, 1980; Hallegraeff and Reid, 1986). Seasonal patterns demonstrate slight variation in the diatom and dinoflagellate succession, with predominately a diatom peak spring bloom in 4th or 5th month, followed by shorter bloom peaks in the 7th, 8th and 9th months. Diatoms blooms are evident in the spring summer months of CW2, CW5 and CW7. However, low bloom numbers are seen in CW4 waterbodies. Dinoflagellates generally show a dominant peak after the diatom bloom for CW2, CW4 and CW7, though the peak of the bloom can vary. Dinoflagellates appear to be peaking at a similar time to the diatoms in CW5. Phaeocystis blooms appear consistent throughout the typologies, with low numbers measured throughout the year and one or two very short peaks measured during the 4th, 5th or 6th month for CW2 and a short peak in the 8th month for CW4. Microflagellates vary significantly through the typologies with shorter peak duration seen in CW2, or persistent populations, peaking during the summer months, as shown in CW4 and CW5. The variation in monoflagellates could be due to a range of different counting methods within

Table 4

Description of the four attributes required for calculation of elevated phytoplankton counts $\left(I_{\mathrm{e}}\right)$

\begin{tabular}{|c|c|c|c|c|}
\hline Attribute & Threshold & Phytoplankton species & Index & Notation \\
\hline $\begin{array}{l}\text { Phytoplankton } \\
\text { biomass }\end{array}$ & $10 \mu \mathrm{g} \mathrm{1^{-1 }}$ & $\begin{array}{l}\text { Frequency of occurrences where } \\
\text { chlorophyll biomass exceeds threshold }\end{array}$ & chl & {$\left[\sum_{1}^{72}[\mathrm{chl}]_{\mathrm{ug} / \mathrm{L}}>10 / \sum_{1}^{300}\right.$ Total $\left._{\text {chlorophyll }}\right]$} \\
\hline $\begin{array}{l}\text { High counts of } \\
\text { any single species }\end{array}$ & $10^{6}$ & $\begin{array}{l}\text { Any single species (other than Phaeocystis) } \\
\text { with counts of greater than } 10^{6}\end{array}$ & $S$ & {$\left[\sum_{1}^{72}[\text { Phaeo }]_{\text {cells }}>10^{6} / \sum_{1}^{300}\right.$ Total $\left._{\text {cells }}\right]$} \\
\hline $\begin{array}{l}\text { Eutrophic } \\
\quad \text { Indicator species }\end{array}$ & $10^{6}$ & Phaeocystis sp. & $P$ & {$\left[\sum_{1}^{72}[\mathrm{Phaeo}]_{\text {cells }}>10^{6} / \sum_{1}^{300} \mathrm{Total}_{\text {cells }}\right]$} \\
\hline $\begin{array}{l}\text { High counts of } \\
\text { the total taxa }\end{array}$ & $10^{7}$ & $\begin{array}{l}\text { Any total taxa count with } \\
\text { counts greater than } 10^{7}\end{array}$ & $T$ & {$\left[\sum_{1}^{72}[\text { Total }]_{\text {cells }}>10^{7} / \sum_{1}^{300}\right.$ Total $\left._{\text {cells }}\right]$} \\
\hline
\end{tabular}

Maximum samples (72) is based on a best scenario basis of monthly samples taken over the six year assessment period. 
Table 5

Proposed boundary conditions for Index $1\left[I_{\mathrm{chl}}\right]$ relating to the exceedance of chlorophyll biomass over the generic thresholds set for each boundary classification

\begin{tabular}{llllll}
\hline$I_{\text {chl }}=X_{90 \text { th }}\left[C_{1}, \ldots, \mathrm{C}_{i}\right]$ & High & Good & Moderate & Poor & Bad \\
\hline $\mathrm{C}\left(\mu \mathrm{g} \mathrm{l}^{-1}\right)$ & $\leqslant 10$ & $>10$ and $\leqslant 15$ & $>15$ and $\leqslant 20$ & $>20$ and $\leqslant 25$ & $>25$ \\
\hline
\end{tabular}

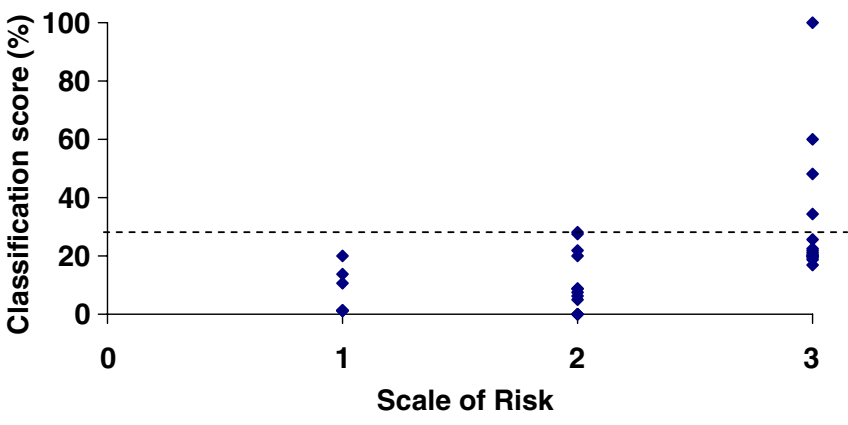

Fig. 5. Mean \% value of all four attributes for elevated count index $\left(I_{\mathrm{e}}\right)$ for risk assigned waterbodies. Dotted line represents suggested classification boundaries for good/moderate boundary based on the dispersal of calculation score $(\%)$.

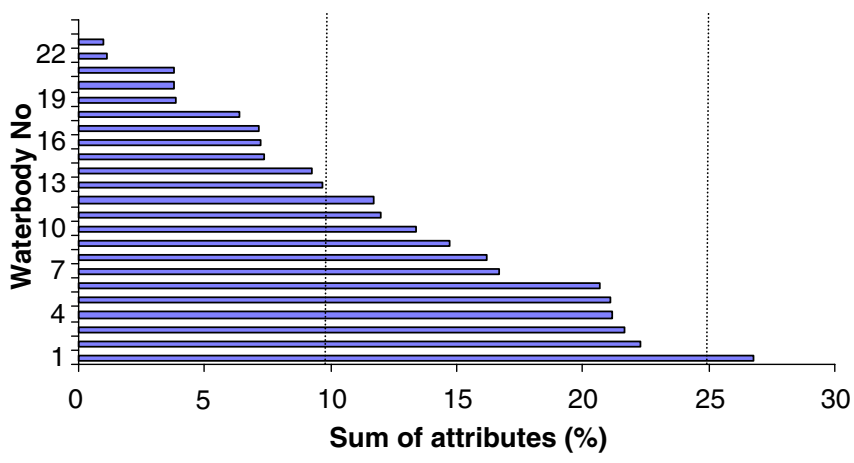

Fig. 6. Rank of classification score (\%) based on the mean of the four attributes of the elevated count index $\left(I_{\mathrm{e}}\right)$. Only type 1 (low risk ) and type 2 (medium risk) waterbodies were used in the ranking. Dotted lines suggest the break in classification boundaries between high/good and good/moderate status.

Table 6

Proposed boundary conditions for $\left(I_{\mathrm{E}}\right)$ relating to the occurrences of elevated taxa counts over a six year period

\begin{tabular}{lllll}
\hline $\begin{array}{l}\text { Normative } \\
\text { definition }\end{array}$ & Index & $\begin{array}{l}\text { Equation }-\{\text { sum } \\
{[T]+[P]+}\end{array}$ & $\begin{array}{l}\text { Classification } \\
\text { boundaries }\end{array}$ & \\
& & $[S]+[\mathrm{chl}] \ldots / 4\} * 100$ & & \\
\hline $\begin{array}{l}\text { Phytoplankton } \\
\text { abundance }\end{array}$ & $I_{\mathrm{E}}$ & $I_{\mathrm{E}}$ : Sum of the & High & $<15 \%$ \\
& & $\begin{array}{l}\text { occurrence of any single } \\
\text { species }\left(>10^{6}\right) \text { plus }\end{array}$ & $\begin{array}{l}\text { Good } \\
\text { Moderate }\end{array}$ & $<30 \%$ \\
& & $\begin{array}{l}\text { Phaeocystis sp. }\left(>10^{6}\right), \\
\text { plus total cell counts } \\
\left(>10^{7}\right) \text { and counts of }\end{array}$ & Poor & $<50 \%$ \\
& & Bad & $>50 \%$ \\
& chlorophyll $>10 \mu g 1^{-1}$ & & \\
& over a six year period & & \\
\hline
\end{tabular}

This index is composed of counts of four attributes within the tool. Samples are taken in growing season between April and September. the UK, and may potentially exclude the smaller monoflagellates from being used within this index.

Using low, moderate and high risk waterbodies, monthly $Z$ scores were calculated and plotted against the type reference curves. Final counts are calculated as a percentage of the times that the $Z$ score falls inside the reference envelope. Mean percentage counts falling within the reference growth envelope was compared between low, medium and high risk waterbodies (Table 7). There are significant differences (one way ANOVA, $p<0.05$ ) between the $\%$ means recorded for diatoms, dinoflagellates and Phaeocystis sp. However, no significant differences was detected between the microflagellates measured within the reference growth curves for low and medium risk waterbodies compared to high risk waterbodies. A preliminary boundary classification of $85 \%$ and $75 \%$ was taken for the high/good and good/moderate boundaries respectively. Arbitrary boundaries were set for moderate, poor and bad at $65 \%, 50 \%$ and $25 \%$ (Table 8 ).

\section{Discussion}

Phytoplanktons are the primary tools in diagnosing eutrophication, not only because they provide the initial response to nutrient enrichment, but because they also encompass a huge range of taxonomic and functional diversity linked closely to the health of marine ecosystems. This paper presented relatively simple indices that can be used in combination to indicate a level of ecological health. These indices all measure some aspect of increased phytoplankton activity related to nutrient enrichment, being either an increase in biomass, increases in the species and taxa counts of phytoplankton and/or alterations in the seasonal cycle. Typically marine systems are complex and difficult to measure, however simple indices relating to cause (nutrients) and effect (increasing abundance of phytoplankton) can be a useful indicator of change, and thus reflective on actual state and deviation away from a natural state.

The first index discussed in this paper is chlorophyll biomass $\left(I_{\text {chl }}\right)$ and reference (high) status is calculated from location of 90th percentile of chlorophyll data against the reference threshold. The second phytoplankton index $\left(I_{\mathrm{e}}\right)$ is based on establishing minimum number of exceedances over total counts which could be seen to represent an undesirable response to nutrient enrichment.

Use of a risk assessment process to allocate preliminary status has been useful testing potential boundaries for WFD classification. In both of these indices $\left(I_{\mathrm{chl}}\right.$ and $\left.I_{\mathrm{e}}\right)$, the break between good/moderate boundaries is well defined, and supports the preliminary boundaries suggested for the indices. However, outputs from the high risk (type 3 ) 
Table 7

Outcomes of index testing using risk assigned waterbodies for CW type 2, 4, 5 and 7

\begin{tabular}{|c|c|c|c|c|c|c|}
\hline \multirow[t]{2}{*}{ Functional Group } & \multicolumn{3}{|c|}{ Type 1 and type 2 waterbodies $(N=15)$} & \multicolumn{3}{|c|}{ Type 3 waterbodies $(N=7)$} \\
\hline & $\operatorname{Min}(\%)$ & $\operatorname{Max}(\%)$ & Mean $(\%)$ & $\operatorname{Min}(\%)$ & $\operatorname{Max}(\%)$ & Mean $(\%)$ \\
\hline Diat & 50 & 100 & 88 & 30 & 100 & 66 \\
\hline Dino & 65 & 100 & 75 & 10 & 100 & 55 \\
\hline Flag & 60 & 100 & 72 & 40 & 100 & 68 \\
\hline Phaeo & 70 & 100 & 85 & 50 & 100 & 70 \\
\hline
\end{tabular}

Min, Max and Mean counts are presented as $\%$ of $Z$ scores that lie within the reference seasonal envelope.

Table 8

Proposed boundary conditions for third index $\left(I_{\mathrm{s}}\right)$ from outcomes of testing risk assigned waterbodies against reference $Z$ scores

\begin{tabular}{|c|c|c|c|c|}
\hline $\begin{array}{l}\text { Normative } \\
\text { definition }\end{array}$ & Index & Definition & $\begin{array}{l}\text { Classification } \\
\text { boundaries }\end{array}$ & \\
\hline $\begin{array}{c}\text { Phytoplankton } \\
\text { abundance }\end{array}$ & $I_{\mathrm{f}}$ & $\begin{array}{l}\text { Number of points } \\
\text { (calculated as a } Z \text { score } \\
\text { based on five year } \\
\text { population mean and } \\
\text { SD) inside reference } \\
\text { envelope. Maximum } 12 \\
\text { points awarded to each } \\
\text { functional group } \\
(n=4) \text { Classification } \\
\text { taken as \% of non } \\
\text { counts against total } \\
\text { counts ( } Z \text { score) }\end{array}$ & $\begin{array}{l}\text { High } \\
\text { Good } \\
\text { Moderate } \\
\text { Poor } \\
\text { Bad }\end{array}$ & $\begin{array}{l}>85 \% \\
>75 \% \\
>65 \% \\
>50 \% \\
>25 \%\end{array}$ \\
\hline
\end{tabular}

waterbodies are not conclusive, and range across the suggested boundary thresholds. This could be caused by the lack of waterbodies demonstrating significantly altered phytoplankton responses. As mentioned, the outputs from the risk assessment allocates waterbodies to a "risk" factor and is not conclusive that an actual impact has occurred, or that the impact is a measurable gradient away from what is recognised as a "good" boundary. Many of England and Wales coastal areas are turbid and well mixed, mitigating the effect of nutrient enrichment on the phytoplankton (Cloern, 2001). Further work on identifying waterbodies with a measurable impact from nutrient enrichment and longer term monitoring of both moderate status and poor/bad status waterbodies is warranted before final acceptance of poor and bad thresholds. However, as the good/moderate boundary is the action level for management under WFD guidelines (WFD), we propose the preliminary boundaries set out in Tables 5 and 6 for WFD classification.

The seasonal succession index $\left(I_{\mathrm{s}}\right)$ demonstrates that strong seasonal patterns do exist within phytoplankton groups, and can be potentially useful as an indicator of ecological health. The examination of seasonality (Figs. 2 and 3) shows the broad temporal variability of phytoplankton populations in WFD coastal waters is subject to a marked seasonal cycle. Functional groupings of diatoms and dinoflagellates show the bloom sequence of high spring and summer concentrations of diatoms, generally followed by a bloom of the dinoflagellates. There are no single bloom periods, but rather a collection of bloom periods, generally starting in March and continuing until September. For diatoms and dinoflagellates, there is some consistency in the seasonal patterns, and it may be possible to define a generic water type pattern, however more work is needed on the other coastal types. Single short peaks are experienced by the Phaeocystis species, but again more work is required from the other typologies to see if this is a constant pattern across the types. Microflagellates can occur in short, frequent peaks, or persist throughout the spring and summer season. More work is required from the other types to determine if this is a type specific response or a function of the sampling and counting techniques. Comparison of risk assigned waterbodies to these preliminary reference curves indicate a significant break in $\%$ boundaries between the type 1 and 2 waterbodies and the type 3 waterbodies (Table 7) allowing preliminary classification ranges to be set for this index (Table 8). However, as with the previous two indices, there is a strong break between good and moderate boundaries, but less specific between the high/good boundary, moderate/poor and poor/bad boundaries. These issues could be related to the lack of either very pristine waterbodies or very disturbed waterbodies in relation to nutrient enrichment. It must be emphasised that the threshold values proposed here are not final and must be validated by testing them against a range of data from sites of different levels of impact. As existing data available to us were not all collected in the same format, some are inappropriate, and others require assumptions or extrapolations to be made. The testing phase is continuing as new data is gathered for the purpose of WFD classification. The degree of confidence in data and in subsequent classification is not presented in this paper, as work is currently underway on determining these.

It is worth noting that these three indices form only a small part of the overall phytoplankton classification, with indices related to a common species list, taxon diversity and phytoplankton community also forming part of the overall phytoplankton "tool box" for ecological classification of UK and ROI marine waters. Combining the tools (indices) together will be an integral step in the WFD classification and an example of the calculation of a final score is shown in Table 9.

\subsection{Conclusions and future directions}

In the risk assessment, we simplify the complex interactions between nutrient availability, production and 
Table 9

Overall classification for the three indices

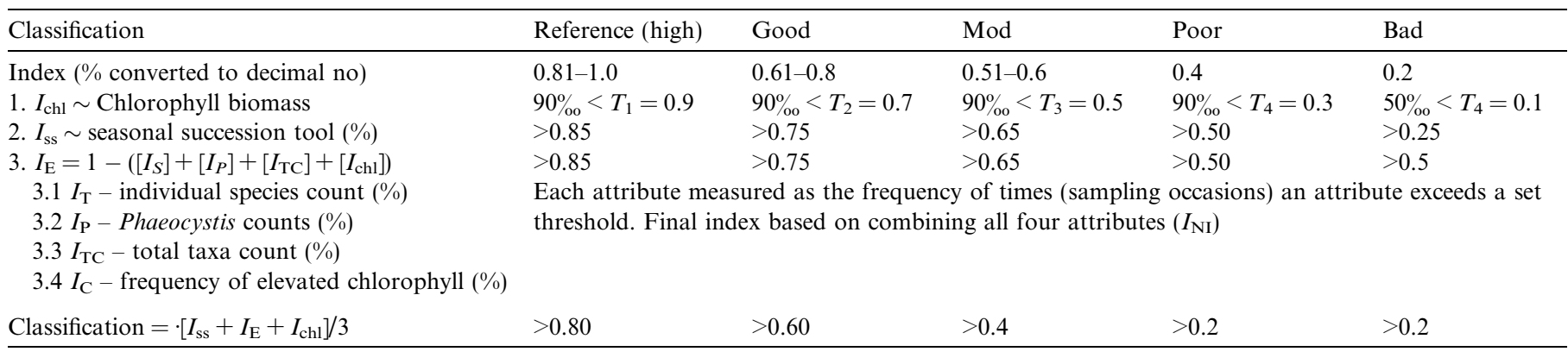

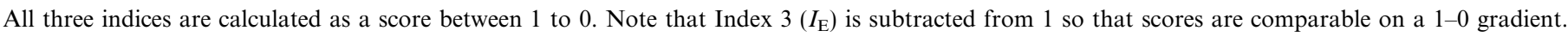

disturbance. Future work will include light dynamics within waterbody types to facilitate a greater confidence in our risk matrix for nutrient pressure. These phytoplankton indices represent a first attempt analyzing on phytoplankton compositional data, tested against degree of nutrient enrichment and establishing (already-accepted) bulk measures (chlorophyll concentrations, Secchi depth, primary production) of trophic status related to a WFD classification status. Indices related to diversity and community composition, needed to align with the final part of the normative definitions are being worked up as part of the classification process under the directive and will be presented in a second paper.

These are preliminary classification boundaries suggested for three phytoplankton indices, based on historical data and typically collected for a myriad of other purposes than WFD compliant monitoring. All of the boundary conditions are based on a deviation from a reference condition. However, the definition of reference condition for this paper has been set by a risk approach, and is not necessarily indicative of the actual status of the waterbody. Further testing needs to undertaken over the next six years of WFD reporting to compare more complete datasets from a greater number of non impacted and impacted waterbodies. As more information becomes available, boundary conditions will potentially be revised as our confidence in the reference data increases.

\section{Disclaimer}

The views expressed in this paper are those of the authors and do not necessarily reflect those of DEFRA, DARD and the EA.

\section{Acknowledgements}

The Authors wish to thank the Environment Agency Water Framework Directive Program and the Scottish and Northern Ireland Forum for Environmental Research (SNIFFER) for funding parts of this work. We would also like to thank Jo Foden, David Mills, Paul Tett, Richard Gowan and Martin Edwards and the support from the DE-
FRA funded project "Development of the Phytoplankton Community Index". We are extremely grateful for the help, advice, guidance, data examples and thought provoking discussions provided by Stephen Malcolm and Suzanne Painting and all members of the Marine Plant Task Team, Dave Jowett and the UK Marine Task Team.

\section{References}

Atchinson, J., 1986. The statistical analysis of compositional data. Chapman \& Hall, London.

Belin, C., Beliaeff, B., Raffin, B., Rabia, M., Ibanez, F., 1995. Phytoplankton time-series data of the French Phytoplankton Monitoring Network: toxic and dominant species. In: Lassus. P., Arzul, G., Erard Le Denn. E., Gentien, P., Marcaillou Le Baut, C. (Eds.), Harmful marine algal blooms - proliférations d'algues nuisibles, Paris-France Lavoisier, pp. 771-776.

Bemen, J., Arrigo, K., Matson, P., 2005. Agricultural runoff fuels large phytoplankton blooms in vulnerable areas of the ocean. Nature 434.

Borja, A., Franco, J., Valencia, V., Bald, J., Muxika, I., Belzunce, M.J., Solaun, O., 2004. Implementation of the European water framework directive from the Basque country (northern Spain): a methodological approach. Marine Pollution Bulletin 48, 209-218.

Boynton, W.R., Hagy, J.D., Murray, L., Stokes, C., Kemp, W.M., 1996. A comparative analysis of eutrophication patterns in a temperate coastal lagoon. Estuaries 19, 408-421.

Bricker, S.B., Clement, C.G. Pirhalla, D.E., Orlando, S.P., Farrow, D.R.G., 1999. National Estuarine Eutrophication Assessment. Effects of nutrient enrichment in the Nation's estuaries. NOAA-NOS Special Projects Office, Silver Spring.

Bricker, S.B., Ferreira, J.G., Simas, T., 2003. An integrated methodology for assessment of estuarine trophic status. Ecological Modelling 169, 39-60.

C.E.C., 1991. Council Directive of 21 May 1991 concerning urban waste water treatment $(91 / 271 /$ EEC). Official Journal of the European Communities, L135 of 30.5.91, pp. 40-52.

C.E.C., 2000. Directive 2000/60/EC of the European Parliament and of the Council of 23 October 2000 establishing a framework for Community action in the field of water policy. Official Journal of the European Communities, L 327, pp. 1-73.

Clarke, K.R., Warwick, R.M., 1994. Change in marine communities: an approach to statistical analysis and interpretation. Natural Environmental Research Council, UK, 144pp.

Cloern, J.E., 2001. Our evolving conceptual model of the coastal eutrophication problem. Marine Ecology Progress Series 210, 223-253.

CSTT, 1994. Comprehensive studies for the purposes of Article 6 of DIR 91/271 EEC, the Urban Waste Water Treatment Directive. Published for the Comprehensive Studies Task Team of Group Coordinating Sea 
Disposal Monitoring by the Forth River Purification Board, Edinburgh.

CSTT, 1997. Comprehensive studies for the purposes of Article $6 \& 8.5$ of DIR 91/271 EEC, the Urban Waste Water Treatment Directive, second edition. Published for the Comprehensive Studies Task Team of Group Coordinating Sea Disposal Monitoring by the Department of the Environment for Northern Ireland, the Environment Agency, 2002 Scottish Environmental Protection Agency and the Water Services Association, Edinburgh.

Edwards, M., John, A.W.G., Johns, D.G., Reid, P.C., 2001. Case-history and persistence of the non-indigenous diatom Coscinodiscus wailesii in the north-east Atlantic. Journal of the Marine Biological Association of the United Kingdom 81 (2), 207-211.

Gailhard, I., Gros, Ph., Durbec, J.P., Beliaeff, B., Belin, C., Nezan, E., Lassus, P., 2002. Variability patterns of microphytoplankton communities along the French coasts. Marine Ecology Progress Series 242, $39-50$.

Gallegos, C.L., Jordan, T.E., Correll, D.L., 1992. Event-scale response of phytoplankton to watershed inputs in a subestuary: timing, magnitude and location of blooms. Limnology and Oceangraphy 37 (4), 813-828.

Gillbricht, M., 1988. Phytoplankton and nutrients in the Helgoland region. Helgolander Meeresuntersuchungen 42, 435-467.

Gowen, R.J., Tett, P., Jones, K.J., 1992. Predicting marine eutrophication: the yield of chlorophyll from nitrogen in Scottish coastal waters. Marine Ecology Progress Series 85, 153-161.

Gowen, R.J., Hydes, D., Mills, D.K., Stewart, B.M., Brown, J., Gibson, C.E., Shammon, T.M., Allen, M., Malcolm, S.J., 2002. Assessing trends in nutrient concentrations in coastal shelf seas: a case study in the Irish Sea. Estuarine and Coastal Shelf Science 54, 927-939.

Hallegraeff, GM., Reid, D.D., 1986. Phytoplankton species successions and their hydrological environment at a coastal station off Sydney. Australian Journal of Marine and Freshwater Research 37, 361-377.

Harding, L., 1994. Long term trends in the distribution of phytoplankton in Chesapeake Bay: roles of light, nutrients and streamflow. Marine Ecology Progress Series 104, 267-291.

Karydis, M., Tsirtsis, G., 1996. Ecological indices: a biometric approach for assessing eutrophication levels in the marine environment. The Science of the Total Environment 186, 209-219.

Kocum, E., Underwood, G.J.C., Nedwell, D.B., 2002. Simultaneous measurement of phytoplanktonic primary production, nutrient and light availability along a turbid, eutrophic UK east coast estuary (the Colne Estuary). Marine Ecology Progress Series 231, 1-12.

Lancelot, C., Billen, G., Sournia, A., Weisse, T., Colijn, F., Veldhuis, M.J.W., Davies, A., Wassman, P., 1987. Phaeocystis blooms and nutrient enrichment in the continental coastal zones of the North Sea. Ambio 16, 38-46.

Larsson, U., Elmgren, R., Wulff, F., 1985. Eutrophication and the Baltic sea: causes and consequences. Ambio 14 (1), 9-14.

Malcolm, S., Nedwell, D., Devlin, M., Hanlon, A., Dare, S., Parker,R., Mills, D., 2002. First Application of the OSPAR comprehensive procedure to Waters around England and Wales. CEFAS Report.
OSPAR Commission, 2003. The OSPAR Integrated Report 2003 on the Eutrophication Status of the OSPAR Maritime Area based upon the first application of the Comprehensive Procedure. Includes "baseline"/ assessment levels used by Contracting Parties and monitoring data (MMC 2003/2/4; OSPAR Publication 2003: ISBN: 1-904426-25-5).

Paerl, H.W., Valdes, L.M., Pinckney, J.L., Piehler, M.F., Dyble, J., Moisander, P.H., 2003. Phytoplankton photopigments as indicators of estuarine and coastal eutrophication. BioScience 53, 953-964.

Painting, S., Devlin, M.J., Rogers, S., Mills, D.K., Parker, E.R., Rees, H.L., 2005. Assessing the suitability of OSPAR EcoQOs for eutrophication vs ICES criteria for England and Wales. Marine Pollution Bulletin 50, 1569-1584.

Rogers, S., Allen, J., Balson, P., Boyle, R., Burden, D., Connor, D., Elliott, M., Webster, M., Reker, J., Mills, C., O'Connor B., Pearson, S., 2003. Typology for the Transitional and Coastal Waters for UK and Ireland. (Contractors: Aqua-fact International Services Ltd, BGS, CEFAS, IECS, JNCC). Funded by Scotland and Northern Ireland Forum for Environmental Research, Edinburgh and Environment Agency of England and Wales, SNIFFER Contract Ref: WFD07 (230/ 8030), 94pp.

Smayda, T.J., 1980. Phytoplankton succession. In: Morris (Ed.), Physiological ecology of phytoplankton I. Blackwell, Oxford, pp. 493570

Smayda, T.J., Reynolds, C.S., 2001. Community assembly in marine phytoplankton: application of recent models to harmful dinoflagellate blooms. Journal of Plankton Research 23, 447-461.

Sommer, U., 1989. Nutrient status and nutrient competition of phytoplankton in a shallow, Hypertrophic lake. Limnology and Oceanography 34 (7), 1162-1173.

Tett, P., 1987. The ecophysiology of exceptional blooms. Rapport et Proces-verbaux des Reunions. Conseil international pour l'Exploration de la Mer 187, 47-60.

Tett, P., et al, 2004. Understanding of undesirable disturbance in the contex of Eutrophication, and the development of UK assessment methodology for coastal and marine waters.: Stage 1 Report: What is undesirable disturbance? Prepared (March 2004) for the Department for Environment, Food and Rural Affairs by: Napier University, Edinburgh; Centre for Environmental, Fisheries and Aquacultural Science, Lowestoft; Department of Agriculture and Rural Development, Belfast; Heriot-Watt University, Edinburgh and Liverpool University, Port Erin Marine Laboratory, Isle of Man. Available from: Defra.

Tett, P., Gowen, R., Grantham, B., Jones, K., Miller, B.S., 1986. The phytoplankton ecology of the Firth of Clyde sea-lochs Striven and Fyne. Proceedings of the Royal Society of Edinburgh B 90, 223 238

Vincent, C., Heinrich, H., Edwards, A., Nygaard K., Haythornthwaite, K., 2002. Guidance on typology, reference conditions and classification systems for transitional and coastal waters. Produced by: CIS Working Group 2.4 (COAST), Common Implementation Strategy of the Water Framework Directive, European Commission: 119 pp. 